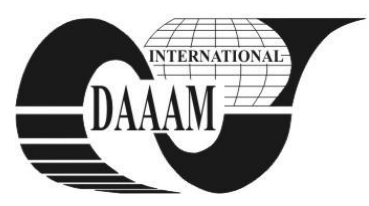

\title{
THEORETICAL ANALYSIS AND RUBBER PAD BENDING OF SELECTED MATERIALS CHOSEN
}

\author{
BILIK, J[ozef]; POMPUROVA, A[nna]; RIDZON, M[artin] \& SUBA, R[oland]
}

\begin{abstract}
The paper is focused on theoretical analysis of bending process using elastic die. There are described analysis of stress state in the bend and influence of spherical stress tensor increasing on bending process. There are also results of experiments with two selected materials - STN 411321 steel, widely used for medium complexity drawings and galvanically zinc coated DP 450 duplex steel, used for parts production in automotive industry. The main areas of experiments were spring-back angle observation and determination of suitable parameters for bending above mentioned materials.

Key words: rubber pad bending, non-rigid die, spherical stress tensor, spring-back angle
\end{abstract}

\section{INTRODUCTION}

The bending - one of basic forming operations is widely used in industrial production. One of bending methods is also bending by elastic tool using rubber and polyurethane. In most cases the rigid die is substituted by rubber pad with hardness 50 - 80 ShA or polyurethane pad with hardness 75 - 85 ShA for thinner sheets with strength up to $400 \mathrm{MPa}$ and with hardness 90 - 95 ShA for thicker sheets with higher strength. The bending with elastic tool has many benefits as certain degree of versatility of die, the possibility of bending surface treated sheets without damaging the surface, die did not create any undesirable tool marks on the surface even during bending of sheets without surface treatment. The additional compressive stresses created by rubber pressure beneficially influences also formability of bent material. Certain advantage can be also possibility of spring-back angle decreasing without the necessity to eliminate spring-back angle by tool design. At Ubending with rubber pad there is no need to use allowance as at classical U-bending with rigid pad. This can beneficially influence the precision of bending. Certain disadvantages of bending by non-rigid die are higher bending force and lower lifetime of elastic die pad. The pad lifetime can be increased by using polyurethane and several interchangeable layers of pad (Bača et al., 2010; Ružička et al., 2001).

\section{THEORETICAL ANALYSIS OF RUBBER PAD BENDING PROCESS}

The rubber pad bending uses various shapes of die pads. The character of tangential stresses during rubber (or polyurethanes) pad bending are similar as during bending in rigid tools as can be seen on Fig. 1. The compression generated by elastic tool increases radial compressive stresses in bend. The radial compressive stresses, working in the direction of sheet thickness and perpendicular to tangential stresses direction, result from plasticity condition. Using adjusted energy condition of plasticity the following formula is obtained

$$
\sigma_{r}-\sigma_{t}=\beta \cdot R_{e}
$$

The role of additional compressive stresses (spherical stress tensor) is significant especially during forming (bending) of materials with lower formability. These are created during rubber pad bending by rubber pressure.

The stress tensor $T_{\sigma}$ during rubber pad bending can be formulated as

$$
T_{\sigma}=D_{\sigma}+T_{\sigma}^{O}
$$

$\mathrm{D}_{\sigma}-$ stress deviator, $\mathrm{T}_{\sigma}{ }^{\mathrm{O}}$ - spherical stress tensor

The stress tensor can be formulated by matrix as

$$
\begin{gathered}
\left|\begin{array}{ccc}
\sigma_{1} & 0 & 0 \\
0 & \sigma_{2} & 0 \\
0 & 0 & \sigma_{3}
\end{array}\right|=\left|\begin{array}{ccc}
\sigma_{1}-\sigma_{\mathrm{s}} & 0 & 0 \\
0 & \sigma_{2}-\sigma_{\mathrm{s}} & 0 \\
0 & 0 & \sigma_{3}-\sigma_{\mathrm{s}}
\end{array}\right|+\left|\begin{array}{ccc}
\sigma_{\mathrm{s}} & 0 & 0 \\
0 & \sigma_{\mathrm{s}} & 0 \\
0 & 0 & \sigma_{\mathrm{s}}
\end{array}\right| \\
\sigma_{s}=\frac{\sigma_{1}+\sigma_{2}+\sigma_{3}}{3}
\end{gathered}
$$

$\sigma_{1}=\sigma_{\mathrm{t}}-$ tangential stress in bend, $\sigma_{3}=\sigma_{\mathrm{r}}+\mathrm{p}-$ radial compressive stress in bend from punch increased by rubber pressure $\mathrm{p}$ compared to conventional bending, $\sigma_{2}=p$

Increasing of radial compressive stress by rubber pressure value (of polyurethane, etc.) during bending in bend increases spherical stress tensor component and also increases formability of bent material. It enables also decreasing of minimal bend radius or increasing of bend angle without material failure. Beside this rubber pressure also decreases spring-back angle without the necessity to change tool design (Kostka, 2002; Pernis, 2007; Hrivňák et al. 1992).

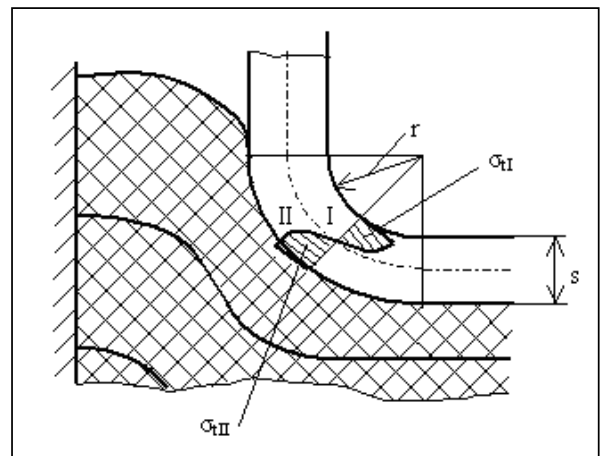

Fig. 1. The character of tangential stresses during rubber (or polyurethanes) pad bending; $\sigma_{\mathrm{tI}}-$ tangential compressive stresses, $\sigma_{\mathrm{tII}}-$ tangential tensile stresses

\section{EXPERIMENTAL RESULTS OF RUBBER PAD BENDING OF SELECTED MATERIALS}

There were two steels used at experiments - classical STN 411321 construction steel for middle complexity drawings and DP 450 double phase steel used in automotive industry.

The chemical composition of tested materials is given in Tables 1 and 2 .

The experiments of rubber pad bending were made on EU 40 tensile test machine because of bending force measurements. The influence of rubber pressure on spring-back angle (or bend 
angle inaccuracy) was observed also. The first values of rubber pressures are just high enough to achieve required bend angle $\alpha$ $=90^{\circ}$. Increasing the rubber pressure enables to observe its influence on bend angle inaccuracy.

\begin{tabular}{|c|c|c|c|c|}
\hline Type & C & Mn & P & S \\
\hline 11321 & max.0,10 & max.0,45 & max.0,030 & max.0,030 \\
\hline
\end{tabular}

Tab. 1. The chemical composition of STN 411321 steel wt. \%

\begin{tabular}{|l|l|l|l|l|l|}
\hline Type & $\mathrm{C}$ & $\mathrm{Mn}$ & $\mathrm{Si}$ & $\mathrm{P}$ & $\mathrm{S}$ \\
\hline DP450 & 0,05 & 0,05 & $<0.40$ & $<0.04$ & $<0.015$ \\
& 0,10 & 1,60 & & & \\
\hline Type & $\mathrm{Al}$ & $\mathrm{Nb}$ & $\mathrm{Ti}$ & $\mathrm{V}$ & $\mathrm{Cr}$ \\
\hline DP450 & 0,02 & $<0,01$ & $<0,01$ & $<0,01$ & $<0,80$ \\
& 0,08 & & & & \\
\hline
\end{tabular}

Tab. 2. The chemical composition of DP 450 wt. \%

The shape and dimensions of sheets used for rubber pad bending are shown on Fig. 2 .

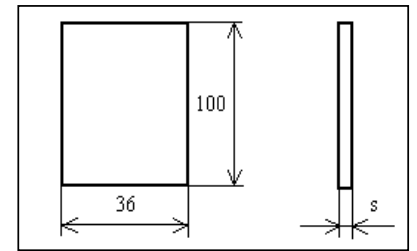

a)

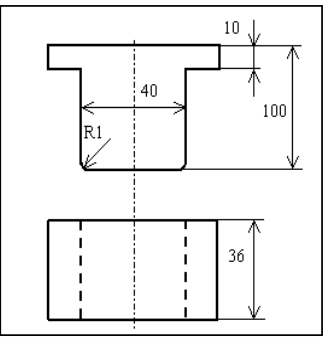

b)
Fig. 2. a) the shape and dimensions of sheets used for rubber pad bending; $b$ ) the shape and dimensions of punch

The shape and dimensions of used die and punch are shown on Figs. 2b, 3 .

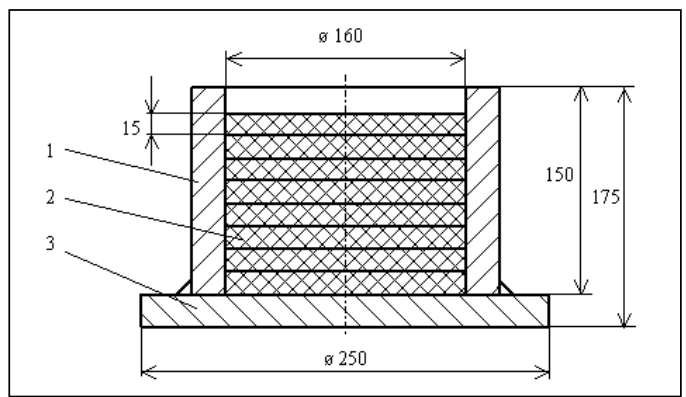

Fig. 3. The shape and dimensions of die; 1 -fixed part of die (frame), 2 - rubber with 70 ShA hardness, 3 - base plate

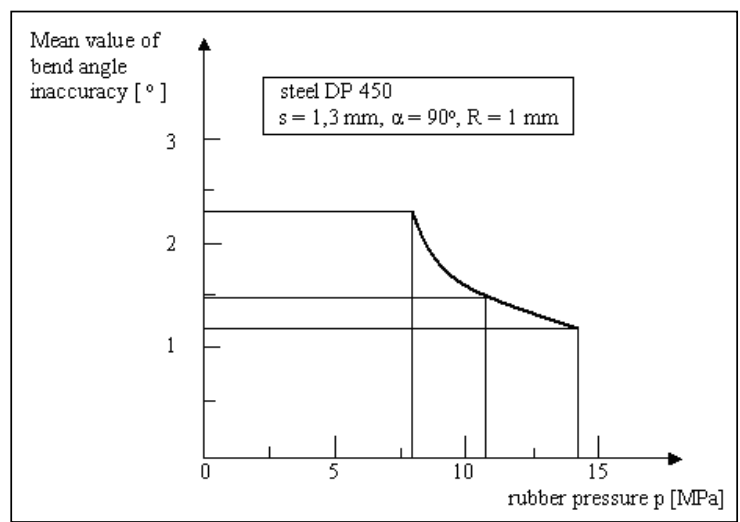

Fig. 4. The dependence of mean value of bend angle inaccuracy (spring-back angle) on rubber pressure during bending of DP 450 steel with thickness $\mathrm{s}=1,3 \mathrm{~mm}$, bend angle $90^{\circ}$ and bend radius $\mathrm{R}=1 \mathrm{~mm}$.

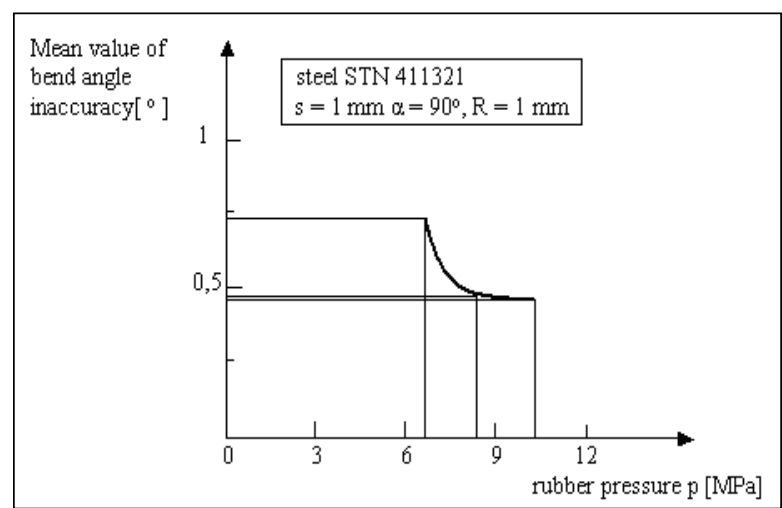

Fig. 5. The dependence of mean value of bend angle inaccuracy (spring-back angle) on rubber pressure during bending of STN 411321 steel with thickness $\mathrm{s}=1,0 \mathrm{~mm}$, bend angle $90^{\circ}$ and bend radius $\mathrm{R}=1 \mathrm{~mm}$.

\section{CONCLUSION}

The measured spring-back angles or bend angle inaccuracies after bending were relatively low. This proves beneficial effect of rubber pressure on decreasing inaccuracy after bending. The test samples were bent using three different values of rubber pressure. Each pressure was applied on several test samples and even the lowest values of pressure were high enough to achieve required bend angle. The influence of rubber pressure on bend angle inaccuracy or spring-back angle was observed at increasing pressures. During the bending of STN 411321 steel can be observed only negligible influence of rubber pressure on bend angle inaccuracy decreas above pressures 8,33 MPa. From this can be concluded that for STN 411321 steel the rubber pressure 8,33 MPa for given conditions is high enough and its further increasing practically did not influence bend angle inaccuracy. During the bending of DP450 steel increasing the pressure up to $13,89 \mathrm{MPa}$ decreased the bend angle inaccuracy. The pressure was not increased further because these conditions were boundary for given rubber and used configuration (free area) and used pressure causes small defects on rubber.

The aim of experiments were study of possibility of rubber using for bending of selected materials STN 411321 and DP 450 and observation of rubber pressure influence on bend angle inaccuracy at small bend radius. The sheet STN 411321 material with thickness $\mathrm{s}=2 \mathrm{~mm}$ was also tested by bending using rubber with hardness $70 \mathrm{ShA}$. It was established that using rubber with this hardness at pressure 13,0 $\mathrm{MPa}$ and sheet thickness $\mathrm{s}=2 \mathrm{~mm}$ causes small defects on upper layer of rubber. So these conditions were boundary for given rubber during bending of this material even from the lifetime point of view. The experiments proved beneficial influence of rubber pressure and increasing of spherical stress tensor component on material formability and decreasing of bend angle inaccuracy. Other benefits of rubber pad bending were already mentioned in the introduction.

\section{REFERENCES}

Bača, J.; Bílik, J.; Tittel, V. (2010). Technology of Forming, Publisher STU, ISBN 978-80-227-3242-0, Bratislava

Hrivňák, A.; Podolský, M.; Domazetovič, V.(1992). Theory of Forming and Tools. Alfa, ISBN 80-05-01032-X, Bratislava

Kostka, P.(2002). Metal Forming, Publisher STU, ISBN 80227-1801-7, Bratislava

Pernis, R.(2007). Theory of metal forming. TnU AD, ISBN 978-80-8075-244-6, Trenčín

Ružička, K.; Zakirov, I.M.; Martyanov, A.G.(2001). Rotary shaping with the use of elastic mediums. Vydavatel'stvo STU, ISBN 80-227-1481-X, Bratislava 